\title{
Subclinical cardiovascular disease markers and vitamin D deficiency in non-dialysis chronic kidney disease patients
}

\author{
Cristina Căpuşăă ${ }^{1,2}$, Gabriel Stefann ${ }^{1,2}$, Simona Stancu ${ }^{1,2}$, Andrea llyes², Nicoleta Dorobanțu², \\ Gabriel Mircescu ${ }^{1,2}$
}

\author{
${ }^{1}$ Nephrology Department, Carol Davila University of Medicine and Pharmacy, \\ Bucharest, Romania \\ "“Dr Carol Davila” Teaching Hospital of Nephrology, Bucharest, Romania
}

Submitted: 16 January 2015

Accepted: 2 March 2015

Arch Med Sci 2016; 12, 5: 1015-1022

DOI: 10.5114 /aoms.2016.61911

Copyright (c) 2016 Termedia \& Banach

\section{Abstract}

Introduction: Since 25-hydroxyvitamin D (25(OH)D) deficiency has been linked to an increased risk for cardiovascular disease (CVD) in the hemodialysis population, we aimed to determine the relationship between serum 25(OH)D level and markers of subclinical CVD in non-dialysis chronic kidney disease (CKD) patients.

Material and methods: This cross-sectional, single-center study prospectively enrolled 87 clinically stable CKD patients (median age: 61 (57-66) years, $51 \%$ male, median estimated glomerular filtration rate (eGFR): $32(27-37) \mathrm{ml} / \mathrm{min}$ ). Five markers of subclinical CVD were assessed: intima-media thickness, abdominal aortic calcifications (AAC) using the Kauppila score, cardio-ankle vascular index, ankle-brachial index (ABI) and interventricular septum thickness.

Results: Vascular (37\%), glomerular (23\%) and interstitial (18\%) nephropathies were the main causes of CKD. $25(\mathrm{OH}) \mathrm{D}$ had a median value of $14(12.5-17.1) \mathrm{ng} / \mathrm{ml}$, and its levels decreased with eGFR $(r s=0.19 ; p=0.04)$. Patients with $25(\mathrm{OH}) \mathrm{D}$ deficiency (54\%) were older, had a higher serum alkaline phosphatase level, lower ABI and higher AAC score. There were no differences between the two groups regarding other traditional or non-traditional risk factors for atherosclerosis. The association between subclinical CVD markers and 25(OH)D was further evaluated in multivariable binomial logistic regression models adjusted for CV risk factors. Lower 25(OH)D level was retained as an independent predictor only for pathological ABI.

Conclusions: This is the first study to evaluate the relationship between a large set of subclinical CVD markers and 25(OH)D deficiency in non-dialysis CKD patients. We found that hypovitaminosis $D$ is associated with subclinical peripheral arterial disease, independently of other cardiovascular risk factors.

Key words: 25-hydroxyvitamin D deficiency, cardiovascular disease, nondialysis chronic kidney disease, peripheral arterial disease.

\section{Introduction}

Cardiovascular disease (CVD) is the primary cause of morbidity and mortality in chronic kidney disease (CKD) patients [1, 2]. Both traditional and non-traditional risk factors for atherosclerosis have been associated

\author{
Corresponding author: \\ Gabriel Stefan MD \\ "Dr Carol Davila" \\ Teaching Hospital \\ of Nephrology \\ Renal Registry \\ Calea Griviței Nr. 4 \\ Sector 1 \\ 010731 Bucharest, Romania \\ Phone: +40724906188 \\ E-mail: gabriel_stefan@ \\ rocketmail.com
}


with the increased cardiovascular risk in this population [3]. Clinical interventions on these factors were not as effective as in the general population, mainly because of the unique CKD setting $[4,5]$. The identification of novel mechanisms that predispose to CVD in the milieu of CKD may prove useful in the development of new targeted therapies.

Vitamin D deficiency, defined as reduced 25-hydroxyvitamin $\mathrm{D}(25(\mathrm{OH}) \mathrm{D})$ levels, is present in the majority of CKD patients. In addition to its classical association with mineral and bone disorders, 25(OH)D deficiency has also been linked to an increased risk for CVD, especially in hemodialysis patients [6-8]. However, whether such an effect is present in non-dialysis CKD patients is largely unknown, since the few studies addressing this issue reported inconsistent results [9-11].

We therefore aimed to investigate the relationship between $25(\mathrm{OH}) \mathrm{D}$ deficiency and markers of cardiovascular damage in non-dialysis CKD patients.

\section{Material and methods}

\section{Subjects}

This prospective, cross-sectional study enrolled 87 patients selected from those admitted to the Dr. Carol Davila Teaching Hospital of Nephrology in a 6-month period. Patients were asked to participate in the study if they were over 18 years of age, had an estimated glomerular filtration rate (eGFR) $<60 \mathrm{ml} / \mathrm{min} / 1.73 \mathrm{~m}^{2}$ (abbreviated Modification of Diet in Renal Disease (MDRD) equation) on two occasions in a 3-month period, and were not on vitamin D supplementation. Patients with end-stage renal disease (ESRD), heart failure, acute coronary event, stroke and clinically manifested peripheral artery disease in the last 6 months, atrial fibrillation, malignancy and active inflammation (C-reactive protein (CRP) $>12 \mathrm{mg} / \mathrm{l}$ ) were excluded.

The study protocol was approved by the local Ethics Committee. All subjects signed an informed consent form prior to any study procedure.

\section{Methods}

Systematic data were obtained for every patient using a standardized questionnaire, which included traditional cardiovascular risk factors such as age, gender, body mass index (BMI), smoking status, hypertension (defined as a blood pressure $\geq 140 / 90 \mathrm{~mm} \mathrm{Hg}$ in non-diabetics, $\geq 130 / 80 \mathrm{~mm} \mathrm{Hg}$ in diabetics or use of anti-hypertensive medication), diabetes mellitus (defined as a plasma fasting glucose $>126 \mathrm{mg} / \mathrm{dl}$ or use of anti-diabetic medication), lipid profile (cholesterol, triglycerides) and non-traditional cardiovascular risk factors - CKD (etiology, eGFR, proteinuria, albuminuria), calcium-phosphate metabolism parameters (serum parathyroid hormone, $25(\mathrm{OH}) \mathrm{D}$, total calcium, phosphate, total alkaline phosphatase), inflammation (CRP, serum albumin), and serum uric acid.

Serum vitamin D was measured in fresh blood samples using a $25(\mathrm{OH}) \mathrm{D}$ electrochemiluminescence immunoassay. Patients were categorized into two groups based on the commonly used cutoff value of $15 \mathrm{ng} / \mathrm{ml}$ : vitamin $\mathrm{D}$ deficient or sufficient [12]. To convert nanograms per milliliter to nanomolar values, one should multiply by 2.496 .

The severity of cardiovascular damage was assessed by measurements of intima-media thickness (IMT), abdominal aortic calcifications score (AAC), ankle-brachial index (ABI) - as markers of atherosclerotic disease - cardio-ankle vascular index (CAVI) as a marker of arterial stiffness, and interventricular septum thickness (IVS) as an index of left ventricular hypertrophy.

Intima-media thickness was determined by B-mode ultrasonography of the carotid artery with a transducer frequency of $7 \mathrm{MHz}$. Up to $4 \mathrm{~cm}$ of the common carotid artery, the carotid bifurcation and the internal carotid $2 \mathrm{~cm}$ distally from the bifurcation were scanned bilaterally using longitudinal and transverse sections. Intima-media thickness was defined as the distance between the leading edge of the first echogenic line (lumen-intima interface) and the second echogenic line (media-adventitia interface) in plaque-free arterial segments. Abdominal aortic calcifications score was evaluated on a lateral lumbar X-ray (acquired in the standing position), as described by Kauppila et al. [13]. Ankle-brachial index and CAVI were measured with the subjects in supine position at rest for at least 10 minutes by trained technicians using the VaSera VS-1000 screening device (Fukuda Denshi, Tokyo, Japan) as described by the manufacturer. Interventricular septum thickness thickness was assessed in diastole using two-dimensional M-mode echocardiography with a $2.5 \mathrm{MHz}$ transducer. All measurements were performed under blind conditions.

\section{Statistical analysis}

All variables included in the analysis were verified for normality using the Shapiro-Wilk test. Continuous variables are presented as mean or median and 95\% confidence interval, according to their distribution, and categorical variables as percentages. Maximum CAVI, IMT and minimum $A B I$ of the bilateral values were used in analysis. Group comparisons were performed with Student's $t$ test, the $\chi^{2}$ test, and the Mann-Whitney $U$ test, as appropriate. The Spearman test was used to assess correlations.

Multivariable-adjusted binomial logistic regression analyses were performed in separate models 
using $\mathrm{ABI}$ (higher or lower than 0.9), CAVI (higher or lower than 9), IMT (higher or lower than $0.1 \mathrm{~cm}$ ), AAC (higher or lower than 1) and IVS (higher or lower than $10 \mathrm{~mm}$ ) as the dependent variable [14-16]. Serum 25(OH)D concentration was used as the independent variable and adjustments were made for age, gender, BMI, smoking status, diabetic status, mean blood pressure (MBP), eGFR (MDRD4), serum uric acid, CRP, cholesterol, triglycerides, serum parathyroid hormone (PTH), serum phosphate, and serum alkaline phosphatase. For the regression analysis, variables were log transformed to satisfy assumptions of normality.

For all tests, a $p$-value $<0.05$ was considered statistically significant. Analyse-it (Analyse-it Software, Ltd., Leeds, UK) and SPSS (SPSS Inc., Chicago, IL, USA) software were used to analyze the data.

\section{Results}

The studied population had a median age of 61 (57-66) years, and 51\% were male. Most of the patients were in stage 3B or 4 CKD (37\% and $28 \%)$. Vascular nephropathy, glomerulonephritis and interstitial nephropathies were the main primary renal diseases. Although $23 \%$ of patients had diabetes mellitus, only $6 \%$ were considered to have diabetic nephropathy. Arterial hypertension was found in $82 \%$ of the studied subjects (Table I). As for treatment, $79 \%$ received a renin-angiotensin system blocker (angiotensin-converting enzyme inhibitors or angiotensin receptor blockers), 56\% received $\beta$-blockers, $34 \%$ calcium channel blockers and $20 \%$ diuretic therapy. Statin therapy was rather scarce $(21 \%)$, while more than half of the patients received antiaggregant therapy (52\%).

Vitamin D had a median value of 14 (12.5-17.1) $\mathrm{ng} / \mathrm{ml}$, and its levels decreased with the eGFR ( $r s=$ $0.19 ; p=0.04)$. Patients with $25(\mathrm{OH}) \mathrm{D}$ deficiency (54\%) were older and had a higher serum alkaline phosphatase level. However, there was no difference between the two groups regarding other traditional and non-traditional risk factors for atherosclerosis. Furthermore, patients with 25(OH)D shortage had similar eGFR and proteinuria as patients with higher vitamin D levels (Table I). Also, we found no relationship between the medication received and vitamin $D$ deficiency.

In the univariate analysis, a relationship between low vitamin $D$ status and arterial disease was presumed since lower $\mathrm{ABI}(p=0.05)$ and a higher AAC score $(p=0.03)$ were found in this group. However, the other non-invasive markers of cardiovascular damage were similar between the studied groups (Table I). Low levels of vitamin D were correlated with increased aortic calcification scores $(r s=-0.23, p=0.03)$, but serum vitamin $D$ levels were not associated with $\mathrm{ABI}(r s=0.20$, $p=0.06)$, CAVI $(r s=-0.04, p=0.7)$, IMT ( $r s=-0.13$, $p=0.22)$ or IVS thickness ( $r s=0.004, p=0.9$ ).

The association between vascular disease subclinical markers and 25(OH)D was further evaluated in multivariable binomial logistic regression models adjusted for cardiovascular risk factors. Serum vitamin D was retained as an independent predictor only for pathological ABI (Table II).

\section{Discussion}

In the present observational prospective study, we found that hypovitaminosis $D$ is associated with subclinical peripheral arterial disease in non-dialysis CKD patients. Furthermore, the statistical power of this correlation remained after adjusting for traditional and non-traditional cardiovascular (CV) risk factors. To the best of our knowledge, this is the first study to evaluate the relationship between a large number of subclinical cardiovascular damage markers and vitamin D deficiency in non-dialysis CKD patients.

The biologically active form of vitamin D, 1,25-dihydroxyvitamin $\mathrm{D}\left(1,25(\mathrm{OH})_{2} \mathrm{D}\right.$; calcitriol), can be difficult to accurately measure since the circulating concentration can be 1000 times lower than that of $25(\mathrm{OH}) \mathrm{D}$ (calcidiol) due to the shorter half-life time. Thus, the most commonly used measure of vitamin D status is the $25(\mathrm{OH}) \mathrm{D}$ assay [17]. In CKD the ability to generate active vitamin $D$ is markedly impaired by the reduction in nephron mass, and the hyperphosphatemia-induced increase in levels of fibroblast growth factor 23, which inhibits the renal hydroxylation and accelerates its catabolism [18]. Furthermore, the 25(OH)D level declines as the glomerular filtration rate falls. The reason for this is not clear; it may be due to environmental factors such as diet, less sun exposure or to uremic and hyperparathyroidism inhibition of the 25-hydroxylation of cholecalciferol in the liver [19]. At present, there is no consensus regarding the optimal $25(\mathrm{OH}) \mathrm{D}$ level for skeletal and extra-skeletal health. Generally, 25(OH)D levels below $30 \mathrm{ng} / \mathrm{ml}$ are considered insufficient and levels below $15 \mathrm{ng} / \mathrm{ml}$ are considered deficient [20]. According to these cutoffs, $76 \%$ of CKD patients display either vitamin D deficiency (42\%) or insufficiency (34\%) [21]. We found a similar proportion of patients with $25(\mathrm{OH}) \mathrm{D}$ deficiency $(54 \%)$ in our cohort.

Low 25(OH)D levels in patients with CKD and ESRD have been associated with a higher risk of all-cause mortality [9, 22-24]. Epidemiological studies, mainly in the general population, reported that moderate to severe vitamin D deficiency was related to an increased risk for cardiovascular events, peripheral vascular disease, hypertension, and congestive heart failure [25-29]. Vitamin D deficiency might affect the cardiovascular system 
Table I. Investigated parameters in study groups

\begin{tabular}{|c|c|c|c|c|}
\hline Parameter & $\begin{array}{c}\text { All } \\
N=87\end{array}$ & $\begin{array}{c}25(\mathrm{OH}) \mathrm{D}<15 \\
\mathrm{ng} / \mathrm{ml} \\
(n=47)\end{array}$ & $\begin{array}{c}25(\mathrm{OH}) \mathrm{D} \geq 15 \\
\mathrm{ng} / \mathrm{ml} \\
(n=40)\end{array}$ & $P$-value ${ }^{*}$ \\
\hline \multicolumn{5}{|l|}{ Traditional risk factors for atherosclerosis: } \\
\hline Male (\%) & 51 & 53 & 65 & 0.2 \\
\hline Age [years] & $61(57-66)$ & $66(60-71)$ & $57(53-64)$ & 0.02 \\
\hline $\mathrm{BMI}\left[\mathrm{kg} / \mathrm{m}^{2}\right]$ & $27(25.8-28.3)$ & $26.8(24.5-29)$ & $27.3(25.6-28.3)$ & 0.9 \\
\hline Smokers (\%) & 6 & 2 & 10 & 0.1 \\
\hline Cholesterol [mg/dl] & $190(176-210)$ & $183(172-196)$ & $206.5(172-216)$ & 0.5 \\
\hline Triglycerides [mg/dl] & $150(132-173)$ & $163(132-180)$ & $136(125-173)$ & 0.5 \\
\hline MBP $[\mathrm{mm} \mathrm{Hg}]$ & $96(91.7-98.3)$ & $96.7(93.3-100)$ & $93.3(88.3-100)$ & 0.1 \\
\hline Arterial hypertension (\%) & 83 & 87 & 78 & 0.2 \\
\hline Diabetes mellitus (\%) & 23 & 30 & 15 & 0.1 \\
\hline \multicolumn{5}{|c|}{ Non-traditional risk factors for atherosclerosis: } \\
\hline Uric acid [mg/dl] & $6.1(5.9-6.5)$ & $6.1(5.8-6.5)$ & $6.2(5.7-7.1)$ & 0.6 \\
\hline \multicolumn{5}{|l|}{ Chronic kidney disease: } \\
\hline \multicolumn{2}{|l|}{ Primary renal disease (\%): } & & & 0.8 \\
\hline Glomerulonephritis & 23 & 19 & 28 & \\
\hline Diabetic nephropathy & 6 & 9 & 3 & \\
\hline Interstitial nephropathies & 18 & 19 & 18 & \\
\hline Hereditary nephropathies & 7 & 6 & 7 & \\
\hline Vascular nephropathy & 37 & 38 & 34 & \\
\hline Other/unknown & 9 & 9 & 10 & \\
\hline \multicolumn{2}{|l|}{ CKD stage $(\%):$} & & & 0.3 \\
\hline $3 \mathrm{~A}$ & 22 & 15 & 30 & \\
\hline $3 B$ & 37 & 38 & 35 & \\
\hline 4 & 28 & 32 & 25 & \\
\hline 5 & 13 & 15 & 10 & \\
\hline $\mathrm{eGFR}[\mathrm{ml} / \mathrm{min}]$ & $32(27-37)$ & $31(23-36)$ & $35.6(27-42.6)$ & 0.09 \\
\hline Proteinuria [g/day] & $0.71(0.45-0.96)$ & $0.92(0.51-1.33)$ & $0.46(0.19-0.73)$ & 0.07 \\
\hline Albuminuria [g/day] & $0.53(0.33-0.72)$ & $0.7(0.38-1.03)$ & $0.32(0.14-0.5)$ & 0.1 \\
\hline \multicolumn{5}{|c|}{ Calcium-phosphate metabolism parameters: } \\
\hline$\underline{\mathrm{PTH}}[\mathrm{pg} / \mathrm{ml}]$ & $89.4(70.5-111)$ & $92.5(64.4-211)$ & $82.8(65.1-109)$ & 0.1 \\
\hline $25(\mathrm{OH}) \mathrm{D}[\mathrm{ng} / \mathrm{ml}]$ & $14(12.5-17.1)$ & $10.4(9.11-12)$ & $20.1(18.6-21.8)$ & $<0.01$ \\
\hline Total calcium $[\mathrm{mg} / \mathrm{dl}]$ & $9.6(9.4-9.8)$ & $9.6(9.5-9.9)$ & $9.55(9.3-9.8)$ & 0.4 \\
\hline Serum phosphate [mg/dl] & $3.6(3.4-3.7)$ & $3.7(3.4-3.8)$ & $3.45(3.1-3.7)$ & 0.09 \\
\hline Serum alkaline phosphatase [U/I] & $78(68-93)$ & $92(71-103)$ & $68.5(64-85)$ & 0.02 \\
\hline \multicolumn{5}{|l|}{ Inflammation: } \\
\hline Serum albumin $[\mathrm{g} / \mathrm{dl}]$ & $4.5(4.36-4.64)$ & $4.4(4.23-4.65)$ & $4.56(4.4-4.7)$ & 0.1 \\
\hline $\mathrm{CRP}[\mathrm{mg} / \mathrm{dl}]$ & $3(3-4)$ & $3(3-5)$ & $3(3-4)$ & 0.2 \\
\hline Non-invasive measurements of atherosc & and arterial stiffne & & & \\
\hline IMT $[\mathrm{cm}]$ & $0.07(0.06-0.08)$ & $0.08(0.06-0.09)$ & $0.06(0.06-0.09)$ & 0.4 \\
\hline CAVI & $10.1(9.4-11.1)$ & $11(9.6-11.2)$ & $9.75(9.2-10.9)$ & 0.3 \\
\hline $\mathrm{ABI}$ & $1.07(1.03-1.1)$ & $1.05(0.99-1.08)$ & $1.09(1.04-1.1)$ & 0.05 \\
\hline Aortic calcification score & $1(0-2)$ & $2(0-3)$ & $0(0-1)$ & 0.03 \\
\hline Ventricular septum [mm] & $10(9.4-11)$ & $10(9-11.3)$ & $10(9-11)$ & 0.3 \\
\hline
\end{tabular}

${ }^{*} 25(\mathrm{OH}) \mathrm{D}<15 \mathrm{ng} / \mathrm{ml}$ vs. $\geq 15 \mathrm{ng} / \mathrm{ml}$. ABl - ankle brachial index, BMl-body mass index, CAVI - cardio ankle vascular index, CKD - chronic kidney disease, CRP - C-reactive protein, eGFR - estimated glomerular filtration rate, IMT - intima media thickness, MBP - mean blood pressure, PTH - parathyroid hormone. 
Table II. Relationship between the five studied non-invasive markers of cardiovascular damage and the cardiovascular risk factors in separate models of multivariable-adjusted binary logistic regression analysis

\begin{tabular}{|c|c|c|c|c|}
\hline Model & Variable & Beta & $95 \% \mathrm{Cl}$ of beta & $P$-value \\
\hline \multirow[t]{4}{*}{$A B I^{*}$} & Age & 1.11 & $1.01-1.22$ & 0.02 \\
\hline & $25(\mathrm{OH}) \mathrm{D}$ & 0.84 & $0.71-1.00$ & 0.05 \\
\hline & Uric acid & 2.39 & $1.24-4.58$ & $<0.01$ \\
\hline & Constant & 0.00 & & $<0.01$ \\
\hline \multirow[t]{3}{*}{$\mathrm{IMT}^{\dagger}$} & Age & 1.13 & $1.06-1.20$ & $<0.01$ \\
\hline & Male gender & 0.25 & $0.06-0.96$ & 0.04 \\
\hline & Constant & 0.00 & & $<0.01$ \\
\hline \multirow[t]{4}{*}{$\mathrm{CAVI}^{\ddagger}$} & Age & 1.22 & $1.10-1.34$ & $<0.01$ \\
\hline & Male gender & 0.09 & $0.01-0.59$ & 0.01 \\
\hline & BMI & 0.84 & $0.71-0.99$ & 0.04 \\
\hline & Constant & 0.05 & 0.05 & 0.12 \\
\hline \multirow[t]{2}{*}{ Aortic calcification score ${ }^{A}$} & Age & 1.09 & $1.05-1.14$ & $<0.01$ \\
\hline & Constant & 0.00 & & $<0.01$ \\
\hline \multirow[t]{6}{*}{ Ventricular septum $\S$} & Age & 1.05 & $1.01-1.09$ & $<0.01$ \\
\hline & Male gender & 0.21 & $0.07-0.66$ & $<0.01$ \\
\hline & Cholesterol & 0.98 & $0.97-0.99$ & 0.03 \\
\hline & Triglycerides & 1.00 & $1.00-1.01$ & 0.04 \\
\hline & Serum phosphate & 1.87 & $0.91-3.83$ & 0.08 \\
\hline & Constant & 0.01 & & 0.07 \\
\hline
\end{tabular}

Each model included the same cardiovascular risk factors. Variables entered at step 1 for each model: age, gender, diabetic status, smoking status, 25(OH)D, serum PTH, serum alkaline phosphatase, eGFR (MDRD), uric acid, CRP, cholesterol, MBP, BMI, triglycerides, serum phosphate. ${ }^{\star}$ Cox and Snell $R^{2}=0.23 ; p<0.01,{ }^{\dagger}$ Cox and Snell $R^{2}=0.31 ; p<0.01,{ }^{\ddagger}$ Cox and Snell $R^{2}=0.43 ; p<0.01,{ }^{A}$ Cox and Snell $R^{2}=$ $0.30 ; p<0.01,{ }^{\S}$ Cox and Snell $R^{2}=0.29 ; p<0.01$.

via parathyroid hormone (PTH) dependent and independent mechanisms.

As CKD progresses, the PTH level begins to rise mostly because of the low levels of $25(\mathrm{OH}) \mathrm{D}$, which reduces calcium absorption by the gut and removes the direct inhibitory effect of vitamin $D$ on the parathyroid gland. Parathyroid hormone seems to be an important "cardiotoxin", since high levels were associated with left ventricular hypertrophy in uremic patients [30]. Furthermore, PTH receptors have been identified in the heart, and in vitro experiments proved that PTH induces hypertrophy of cardiomyocytes [31]. Despite a higher mean level of PTH in the vitamin D deficiency patients, there was no significant difference between the studied groups, which could also explain the lack of difference in the ventricular septum thickness.

Independently of PTH, vitamin D appears to have three main protective effects on the cardiovascular system: regulation of the inflammatory process, direct inhibition of cardiac hypertrophy and myocyte proliferation, and regulation of the renin-angiotensin system [32]. Evidence from clinical and animal model studies suggests the existence of a biphasic cardiovascular effect of vitamin D, in which, similar to the shortage effect, higher doses predispose to CVD [33]. Rajasree et al. reported that high levels of $25(\mathrm{OH}) \mathrm{D}$, above $89 \mathrm{ng} / \mathrm{ml}$, were associated with an increased risk of ischemic heart disease [34]. However, the patients in our cohort were rather vitamin D deficient and insufficient (Table I).

In our data, the lack of differences with regard to the majority of traditional cardiovascular risk factors, except for age and serum alkaline phosphatase, could be due to a biunivocal relationship between CKD and atherosclerosis, as vascular nephropathies were highly prevalent irrespective of vitamin D status $[35,36]$. An increased alkaline phosphatase level in CKD patients has been shown to be an important marker for arterial stiffness, since it was associated with arterial calcification in various arterial territories: coronary, carotid, aorta and femoral $[37,38]$. In the CKD setting, vascular muscle cells could undergo 
osteoblastic differentiation and express alkaline phosphatase, which inactivates pyrophosphate - an endogenous inhibitor of hydroxyapatite formation, the net result being medial arterial calcification [39].

Abnormal CAVI and increased carotid IMT are independent predictors of CVD morbidity and mortality in CKD patients [40, 41]. In contrast to previous reports, we found no relationship between these markers and vitamin D deficiency in our population. However, these studies used as controls healthy subjects or patients with vitamin $D$ levels in the normal range $[8,42]$. Since more than $90 \%$ of our patients were vitamin $D$ deficient or insufficient, stratification of inadequate levels of vitamin $D$ in these groups seems to make no difference in terms of arterial stiffness. Interestingly, we found a significantly higher calcification score in the $25(\mathrm{OH}) \mathrm{D}$ deficient group, but this relationship was not retained in the regression analysis. These findings are in line with those of Barreto et al., who in a similar population found that the vitamin D effect on cardiovascular mortality is independent of vascular calcification and stiffness [21]. Taken together, these results indicate that vitamin D levels might be differently associated with the morphologic changes in the arterial wall depending on the clinical context.

The results of our study suggest that the relationship between low vitamin $D$ and $A B I$ as a marker of subclinical arterial disease is due to an independent effect of vitamin D deficiency on the arterial wall. The vitamin $D$ receptor, which mediates the actions of vitamin D, has been found to have a broad tissue distribution, including the cardiovascular system (cardiomyocytes, vascular smooth muscle cells and endothelium) and the immune system (antigen presenting cells, T cells) [17, 43, 44]. The actions of vitamin $D$ on the arterial wall include reduction of smooth muscle cell proliferation and a decrease in vascular inflammation (reduction of pro-inflammatory cytokines such as interleukin-6 (IL-6) and tumor necrosis factor (TNF)- $\alpha$; increased secretion of the anti-inflammatory cytokine IL-10) [45-47]. Moreover, Chitalia et al. demonstrated an association between abnormal vascular endothelial function and vitamin D deficiency in non-dialysis CKD patients using brachial artery flow mediated dilation [48]. Thus, vitamin D seems to be a key player in the atherosclerotic process and an important target for treatment in the context of CKD.

Our study is limited by the relatively small population and the cross-sectional design, which may impede us in identifying other links between vitamin D deficiency and CV risk factors. Furthermore, our results can only suggest a relationship between vitamin $\mathrm{D}$ status and arterial disease and not prove causality. Several potentially confound- ing factors could have influenced our analysis, the most important being the age difference between the two groups, diet and sunlight exposure. However, vitamin D deficiency was associated with a pathologic $A B I$ independent of age in the logistic regression model. Moreover, the patients in the studied groups had similar renal function, which additionally suggests the independent effect of vitamin D on the arterial wall. Blood pressure comparison could have been biased by therapy, since all of our hypertensive patients had well-controlled blood pressure.

In conclusion, the current study shows a high prevalence of vitamin $D$ deficiency in non-dialysis CKD patients. Furthermore, our results suggest an association between low vitamin D status and subclinical peripheral arterial disease, independent of other non- and traditional cardiovascular risk factors.

\section{Conflict of interest}

The authors declare no conflict of interest.

\section{References}

1. Foley RN, Parfrey PS, Sarnak MJ. Epidemiology of cardiovascular disease in chronic renal disease. J Am Soc Nephrol 1998; 9: S16-23.

2. Oh J, Wunsch R, Turzer M, et al. Advanced coronary and carotid arteriopathy in young adults with childhood-onset chronic renal failure. Circulation 2002; 106: 100-5.

3. Vlagopoulos PT, Sarnak MJ. Traditional and nontraditional cardiovascular risk factors in chronic kidney disease. Med Clin North Am 2005; 89: 587-611.

4. Rakhit DJ, Marwick TH, Armstrong KA, Johnson DW, Leano $R$, Isbel NM. Effect of aggressive risk factor modification on cardiac events and myocardial ischaemia in patients with chronic kidney disease. Heart 2006; 92: 1402-8.

5. Kaisar MO, Isbel NM, Johnson DW. Recent clinical trials of pharmacologic cardiovascular interventions in patients with chronic kidney disease. Rev Recent Clin Trials 2008; 3: 79-88.

6. Teng $M$, Wolf $M$, Ofsthun $M N$, et al. Activated injectable vitamin $D$ and hemodialysis survival: a historical cohort study. J Am Soc Nephrol 2005; 16: 1115-25.

7. Wolf M, Shah A, Gutierrez O, et al. Vitamin D levels and early mortality among incident hemodialysis patients. Kidney Int 2007; 72: 1004-13.

8. London GM, Guerin AP, Verbeke FH, et al. Mineral metabolism and arterial functions in end-stage renal disease: potential role of 25-hydroxyvitamin D deficiency. J Am Soc Nephrol 2007; 18: 613-20.

9. Ravani P, Malberti F, Tripepi G, et al. Vitamin D levels and patient outcome in chronic kidney disease. Kidney Int 2009; 75: 88-95.

10. Mehrotra R, Kermah DA, Salusky IB, et al. Chronic kidney disease, hypovitaminosis $D$, and mortality in the United States. Kidney Int 2009; 76: 977-83.

11. Jassal SK, Chonchol M, von Muhlen D, Smits G, Barrett-Connor E. Vitamin D, parathyroid hormone, and cardiovascular mortality in older adults: the Rancho Bernardo study. Am J Med 2010; 123: 1114-20. 
12. Thomas MK, Lloyd-Jones DM, Thadhani RI, et al. Hypovitaminosis D in medical inpatients. N Engl J Med 1998 338: 777-83.

13. Kauppila LI, Polak JF, Cupples LA, Hannan MT, Kiel DP, Wilson PW. New indices to classify location, severity and progression of calcific lesions in the abdominal aorta: a 25 year follow-up study. Atherosclerosis 1997; 132: 245-50.

14. Lang RM, Bierig M, Devereux RB, et al. Recommendations for chamber quantification: a report from the American Society of Echocardiography's Guidelines and Standards Committee and the Chamber Quantification Writing Group, developed in conjunction with the European Association of Echocardiography, a branch of the European Society of Cardiology. J Am Soc Echocardiogr 2005; 18: 1440-63.

15. Holewijn S, den Heijer M, Stalenhoef AF, de Graaf J. Non-invasive measurements of atherosclerosis (NIMA): current evidence and future perspectives. Neth J Med 2010; 68: 388-99.

16. Shirai K, Hiruta N, Song M, et al. Cardio-ankle vascular index (CAVI) as a novel indicator of arterial stiffness: theory, evidence and perspectives. J Atheroscler Thromb 2011; 18: 924-38.

17. Holick MF. Vitamin D deficiency. N Engl J Med 2007; 357: 266-81.

18. Hu P, Hu B, Wang J, Lu L, Qin YH. Modulation of vitamin D signaling is a potential therapeutic target to lower cardiovascular risk in chronic kidney disease. Med Sci Monit 2011; 17: HY14-20.

19. Michaud J, Naud J, Ouimet D, et al. Reduced hepatic synthesis of calcidiol in uremia. J Am Soc Nephrol 2010; 21: 1488-97.

20. Holick MF, Binkley NC, Bischoff-Ferrari HA, et al. Evaluation, treatment, and prevention of vitamin D deficiency: an Endocrine Society clinical practice guideline. J Clin Endocrinol Metab 2011; 96: 1911-30.

21. Barreto DV, Barreto FC, Liabeuf S, et al. Vitamin D affects survival independently of vascular calcification in chronic kidney disease. Clin J Am Soc Nephrol 2009; 4 1128-35.

22. Drechsler C, Verduijn M, Pilz S, et al. Vitamin D status and clinical outcomes in incident dialysis patients: results from the NECOSAD study. Nephrol Dial Transplant 2011; 26: 1024-32.

23. Melamed ML, Astor B, Michos ED, Hostetter TH, Powe NR, Muntner P. 25-hydroxyvitamin D levels, race, and the progression of kidney disease. J Am Soc Nephrol 2009; 20: 2631-9.

24. Pilz S, lodice S, Zittermann A, Grant WB, Gandini S. Vitamin D status and mortality risk in CKD: a meta-analysis of prospective studies. Am J Kidney Dis 2011; 58 374-82.

25. Wang TJ, Pencina MJ, Booth SL, et al. Vitamin D deficiency and risk of cardiovascular disease. Circulation 2008 117: 503-11.

26. Melamed ML, Muntner P, Michos ED, et al. Serum 25-hydroxyvitamin $D$ levels and the prevalence of periphera arterial disease: results from NHANES 2001 to 2004 Arterioscler Thromb Vasc Biol 2008; 28: 1179-85.

27. Forman JP, Giovannucci E, Holmes MD, et al. Plasma 25-hydroxyvitamin $D$ levels and risk of incident hypertension. Hypertension 2007; 49: 1063-9.

28. Pilz S, Marz W, Wellnitz B, et al. Association of vitamin D deficiency with heart failure and sudden cardiac death in a large cross-sectional study of patients referred for coronary angiography. J Clin Endocrinol Metab 2008; 93 : 3927-35.
29. Makariou S, Liberopoulos E, Florentin M, et al. The relationship of vitamin $D$ with non-traditional risk factors for cardiovascular disease in subjects with metabolic syndrome. Arch Med Sci 2012; 8: 437-43.

30. Ganesh SK, Stack AG, Levin NW, Hulbert-Shearon T, Port FK. Association of elevated serum PO(4), CaxPO(4) product, and parathyroid hormone with cardiac mortality risk in chronic hemodialysis patients. J Am Soc Nephrol 2001; 12: 2131-8.

31. Nikodimopoulou M, Liakos S. Secondary hyperparathyroidism and target organs in chronic kidney disease. Hippokratia 2011; 15: 33-8.

32. Levin A, Li YC. Vitamin D and its analogues: do they protect against cardiovascular disease in patients with kidney disease? Kidney Int 2005; 68: 1973-81.

33. Reis JP, Michos ED, von Muhlen D, Miller ER $3^{\text {rd }}$. Differences in vitamin $D$ status as a possible contributor to the racial disparity in peripheral arterial disease. Am J Clin Nutr 2008; 88: 1469-77.

34. Rajasree S, Rajpal K, Kartha CC, et al. Serum 25-hydroxyvitamin D3 levels are elevated in South Indian patients with ischemic heart disease. Eur J Epidemiol 2001; 17: 567-71.

35. Schiffrin EL, Lipman ML, Mann JF. Chronic kidney disease: effects on the cardiovascular system. Circulation 2007; 116: 85-97.

36. Weiner DE, Tabatabai S, Tighiouart H, et al. Cardiovascular outcomes and all-cause mortality: exploring the interaction between CKD and cardiovascular disease. Am J Kidney Dis 2006; 48: 392-401.

37. Taliercio JJ, Schold JD, Simon JF, et al. Prognostic importance of serum alkaline phosphatase in CKD stages 3-4 in a clinical population. Am J Kidney Dis 2013; 62: 703-10.

38. Sigrist MK, Taal MW, Bungay P, Mclntyre CW. Progressive vascular calcification over 2 years is associated with arterial stiffening and increased mortality in patients with stages 4 and 5 chronic kidney disease. Clin J Am Soc Nephrol 2007; 2: 1241-8.

39. Lomashvili KA, Garg P, Narisawa S, Millan JL, O’Neill WC. Upregulation of alkaline phosphatase and pyrophosphate hydrolysis: potential mechanism for uremic vascular calcification. Kidney Int 2008; 73: 1024-30.

40. Preston E, Ellis MR, Kulinskaya E, Davies AH, Brown EA. Association between carotid artery intima-media thickness and cardiovascular risk factors in CKD. Am J Kidney Dis 2005; 46: 856-62.

41. Nakamura K, lizuka T, Takahashi $M$, et al. Association between cardio-ankle vascular index and serum cystatin C levels in patients with cardiovascular risk factor. J Atheroscler Thromb 2009; 16: 371-9.

42. Yadav AK, Banerjee D, Lal A, Jha V. Vitamin D deficiency, CD4+CD28null cells and accelerated atherosclerosis in chronic kidney disease. Nephrology (Carlton) 2012; 17 : 575-81.

43. Takeda M, Yamashita T, Sasaki N, et al. Oral administration of an active form of vitamin D3 (calcitriol) decreases atherosclerosis in mice by inducing regulatory $T$ cells and immature dendritic cells with tolerogenic functions. Arterioscler Thromb Vasc Biol 2010; 30: 2495-503.

44. Ertek S, Akgül E, Cicero AF, et al. 25-Hydroxy vitamin D levels and endothelial vasodilatator function in normotensive women. Arch Med Sci 2012; 8: 47-52.

45. Davies MR, Hruska KA. Pathophysiological mechanisms of vascular calcification in end-stage renal disease. Kidney Int 2001; 60: 472-9. 
46. Guillot X, Semerano L, Saidenberg-Kermanac'h N, Falgarone G, Boissier MC. Vitamin D and inflammation. Joint Bone Spine 2010; 77: 552-7.

47. Muller K, Haahr PM, Diamant M, Rieneck K, Kharazmi A, Bendtzen K. 1,25-Dihydroxyvitamin D3 inhibits cytokine production by human blood monocytes at the post-transcriptional level. Cytokine 1992; 4: 506-12.

48. Chitalia N, Recio-Mayoral A, Kaski JC, Banerjee D. Vitamin D deficiency and endothelial dysfunction in non-dialysis chronic kidney disease patients. Atherosclerosis 2012; 220: 265-8. 